\title{
Marine Turtles of the Western Indian Ocean
}

\author{
Jack Frazier
}

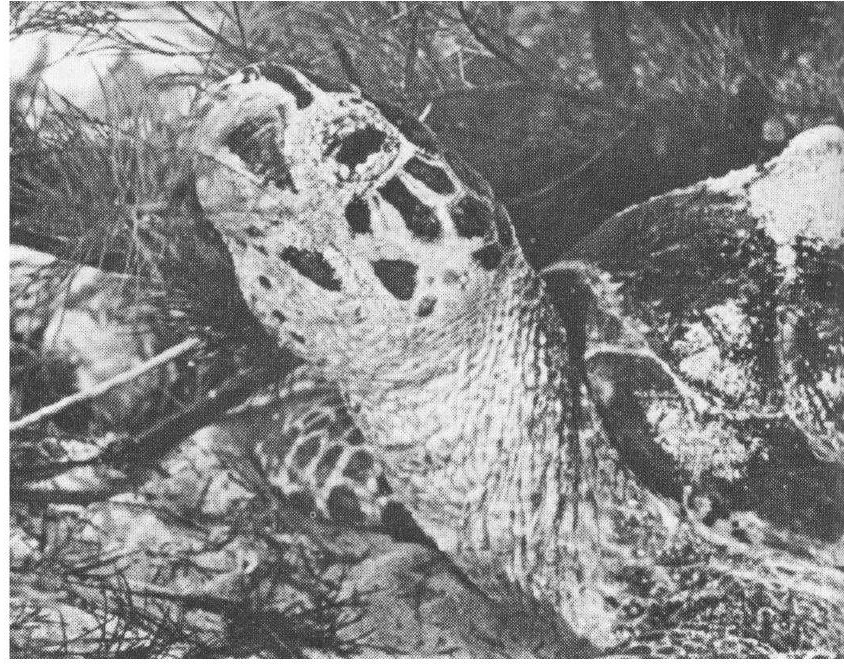

After seven years' study, visiting islands scattered over more than a million square miles of the western Indian Ocean, where once hundreds of thousands of green turtles nested every year, the author's "optimistic estimate" of the number of females nesting today is 5500 . Only eighty years ago 12,000 were taken in one year on Aldabra alone. Over-exploitation by man for food - both of nesting females and eggs - and destruction of nesting habitat, i.e. disturbance of the beaches, are the two factors that are destroying this immensely valuable resource. The author's study was assisted by FPS.

For seven years, 1968-74, I have been studying sea turtles in the western Indian Ocean, and only now do I feel able to report on their status in the area north of Madagascar: Seychelles, British Indian Ocean Territory (BIOT), Gloriosa, Comoros, and offshore islands north-east of Madagascar. Many of the islands studied were once famous for their vast numbers of turtles, which had thrived for untold centuries. But in the last hundred years exploitation by man has reduced the populations, as well as other natural resources, catastrophically, and a survey of the population trends and the status of both the turtles and their nesting and feeding grounds had become urgent. However, getting to small, remote islands is not easy at the best of times, and even when you do it is not always possible to land. The study area covers over a million square miles. In Seychelles alone there are nearly a hundred islands, and even after seven years of study, sailing over tens of thousands of miles of ocean, and walking hundreds of miles of beaches, there are beaches I have still not surveyed and some islands I have never seen. However, I have visited all the most important beaches, and there is no indication that the few unsurveyed ones would invalidate my conclusions.

Only two species of marine turtle are common in the western Indian Ocean: the green Chelonia mydas, famous for its contribution to turtle soup, and the smaller hawksbill Eretmochelys imbricata, known for its beautiful shell that is made into jewellery and curios. Loggerhead, ridley, and leathery turtles are found only rarely in these waters. Estimating the population of an animal that ranges over thousands of miles of ocean, and still guards many important secrets of its life history (e.g. time taken to mature), is something of a "guestimate". However, nesting females coming ashore leave conspicuous tracks and nest pits on the beach, and these can be counted with some 


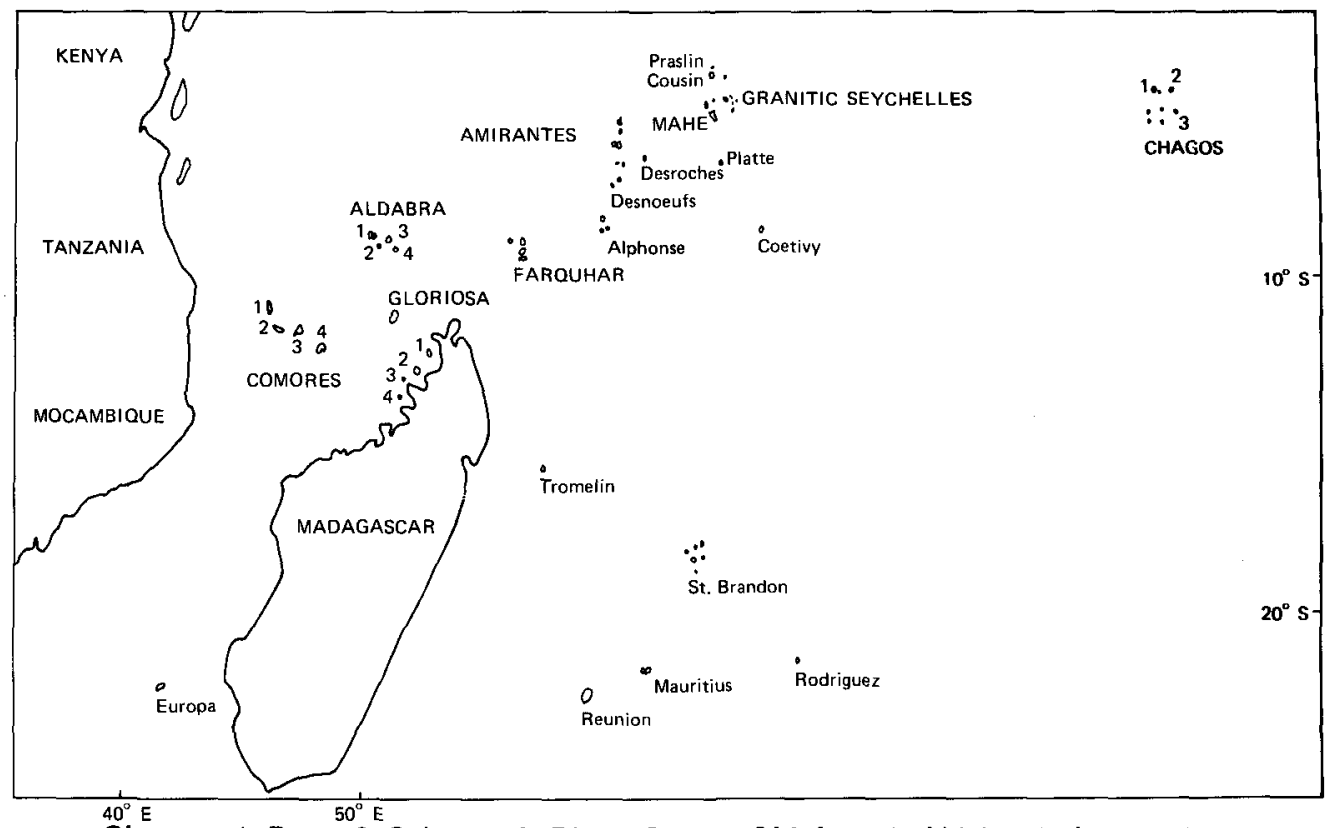

Chagos: 1. Peros 2. Solomon 3. Diego Garcia; Aldabra: 1. Aldabra 2. Assumption 3. Cosmoledo 4. Astove; Comores: 1. Grande Comore 2. Moheli 3. Anjouan 4. Mayotte; Madagascar: 1. Mitsio 2. Nossi Be 3. Nossi Iranja 4. Radama.

accuracy. Green turtle tracks last a few weeks, and the nest pits up to a year; hawksbill tracks last about a week and the nest pits about a month. There are however several points to confuse the issue: females will nest on top of other nests and obscure previous spoor, but in areas of low nesting density this is not important. Moreover, not all nesting attempts result in eggs being laid; as often as not a turtle digs a nest pit and abandons it without laying; if it is fairly recent an experienced observer can usually tell if it contains eggs or not. Females usually nest every two or three years, and lay at roughly fortnightly intervals at least three times in a season-sometimes as many as eight times.

To calculate the annual number of nesting females one must visit a beach several times in a year. With remote islands this may not be possible, and some assuming is needed. One must guess how old the spoor is, and whether or not nesting activity is likely to change during the year (that is, does nesting occur mainly at a certain season?). A careful look at the habitat, colonising beach creepers, and other plants out on the exposed sand, gives a good indication of the amount of disturbance on the beach, and hence how intense nesting has been and is likely to become. Visiting a beach at peak nesting time and then assigning the observed (high) level of nesting activity for the remainder of the year obviously maximises the estimate, as does the assumption that all nest pits contain eggs; a third way is to assume that one female lays only three times a year, and therefore that the annual number of nest pits containing eggs, divided by three, gives an estimate of the number of nesting females - this estimate being maximal for three reasons.

Even using these methods the turtle populations are depressingly small. But more frightening still is the rate at which the habitats needed by the turtles are disappearing; even if they were never again molested by man (pure fantasy) they are doomed in those places where man has taken or ruined their nesting beaches. 


\section{SEYCHELLES AND BIOT}

The Seychelles, soon to be independent, and the British Indian Ocean Territories are spread over a vast area of ocean. BIOT, set up in 1965, includes Chagos Archipelago, and Aldabra, Farquhar, and Desroches Atolls.

\section{Chagos Archipelago}

Once a dependency of Mauritius, the Chagos Archipelago, is the largest area in BIOT, comprising 65 sand cays or (at most) raised reefs. These are scattered over the Great Chagos Bank, which stretches 134 miles from north to south and 74 miles east to west. Despite their isolation and the miles of fine beaches, they are not known as turtle islands. The archipelago was settled in the last century and the original vegetation replaced by coconut plantations, but recently the creole des isles inhabitants have been evacuated to Mauritius. Now the islands are deserted, apart from Diego Garcia, which has an Anglo-American base, so possibly the turtle populations will increase.

In 1970 there was little sign of turtles on Peros, Salomon, and Diego Garcia atolls, although I did not see all the beaches. But on Nelson Island there was intense nesting activity. However, Nelson is so small that this meant only two dozen nest pits, although I was told that 30 to 40 turtles could be caught in a season here. On Peros, I was told, 40 to 50 (over 100 according to another informant) green turtles could be taken in a year, and two or three at Salomon. Altogether, it seems unlikely that more than a few hundred green turtles nest annually in the archipelago. I was also told that up to 200 hawksbills could be caught at Peros and twenty at Salomon; perhaps a maximum of a few hundred hawksbills breed on these islands each year.

The estimates for are "informed guesses" but they are conservative maxima.

\section{Granitic Seychelles}

The only true oceanic islands in the world composed of granite, the Seychelles are a "crumb" left from the breaking up of Gondwanaland millions of years ago. When the French settled these high mountainous islands, toward the end of the 18th century, they were cloaked in forests of valuable endemic hardwoods. Turtles were abundant, and most of the early settlers became involved in the export of chelonian products. But over-exploitation, despite frequent pleas and warnings, virtually exterminated the turtles, the forests, and other renewable natural resources. Today green turtles are not common on the feeding grounds, but there are vast areas of marine pastures which must once have supported countless turtles. Nesting animals are rare; the most concentrated evidence I have seen was sixteen nest pits on Curieuse in 1970, and I have seen nothing comparable since. However, on tiny Cousin Island, now a nature reserve belonging to the ICBP (International Council for Bird Preservation) eight nests were recorded in 1972/73 whereas there were none a few years ago. In all the granitic islands probably only a few dozen green turtles nest each year.

Hawksbills, on the other hand, are common on the reefs, and concentrated nesting occurs. Cousin had over 60 nests in the 1971/72 season, and in all the Seychelles possibly a few hundred nest every year. Tourism seems to have brought an increased demand for hawksbill curios, and a consequent increase in hunting pressure.

But the most worrying thing in Seychelles is not predation but habitat 


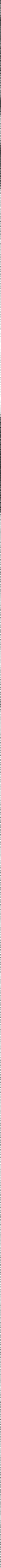


destruction. With increased tourism and socio-economic development, more and more land is being modified for man's purposes while fewer and fewer beaches are left for nesting turtles; on the two largest islands, Mahé and Praslin, where development is most intense, there are very few left at all: If turtles are to be an important resource, not only must hunting be controlled but nesting reserves must be created. Cousin Island is already an important reserve, but more undisturbed beaches will be needed if a significant population is to be sustained. It is highly unlikely that beaches in marine national parks will be undisturbed enough to be good nesting beaches.

\section{Amirantes Islands}

On the Amirante Bank, 133 miles west of Mahé, a string of nine major islands and cays, runs north-south for over 100 miles; one atoll, Desroches, lies to the east of the bank, and two, Alphonse and St François, to the south. Planted with coconuts, each island until recently had a sizeable labour force recruited from Mahé, but one by one they are being deserted due to rising labour and transport costs.

The Amirantes provide vast areas of marine pastures and coral reefs, but have never been known as turtle islands. I have visited most of them, some several times, but found very little evidence of green turtles nesting; Desnoeufs, famous for its millions of breeding sooty terns, had the most. In October 1972 I found 72 nest pits: 31 with eggs, 26 without, and 15 uncertain. By April 1973 there were 45 new nest pits, 17 probably containing eggs. Peak nesting here is evidently in the southern winter, as on Aldabra. Assuming that the pits seen in October represented nests made during the previous three months (almost certainly an underestimate) and that the other half of the six-month nesting season had the same numbers - we arrive at 144 nests a season, which at three nests per turtle means only 48 females. If nesting were as intense throughout the year as in the peak nesting season there would be fewer than 100 females.

On Marie Louise and Desroches probably not more than a dozen females nest each year. Taking the most optimistic view, and including also the handful of tiny cays that I have not been able to examine properly, the total number of nesting green turtles in the Amirantes is only a few hundred, a pitiful number. Early explorers caught that number in a few days.

Hawksbills are common in Amirantes waters, but nesting is inconspicuous. On Remire, once supposed to be an important nesting area, I saw only seven nest pits. At Poivre, the manager said about 50 turtles a year were taken, but many of these were not nesting. I guess fewer than 150 nest yearly.

\section{Aldabra Group}

These islands, composed of raised reef rock, include the most famous turtle islands in the western Indian Ocean. The geographer J. Parsons, describing turtling activities in historic times, says that on Assumption Island 200 to 300 females used to be turned in one night alone. Recently the total catch on Aldabra itself was only 400 to 500 a year.

Aldabra atoll is by far the largest and best known of the group. Its $83 \mathrm{~km}$. of coast, consisting mainly of treacherous dissected limestone with short 'pocket beaches', provides only $3.5 \mathrm{~km}$. of suitable nesting beach, the longest stretch being $1.5 \mathrm{~km}$. long; predictably it is the site of the permanent human 
settlement and, therefore, of most disturbance. In 1970, after thirteen months on the atoll, I estimated that not more than 1000 females breed annually. (This study is to be the subject of a detailed report.) By 1973, however, several short visits revealed a marked increase in nesting activity, at least on the western beaches. In May, before the nesting peak, and in December, during the lull, there was as much evidence of nesting on the western beaches as I had seen at the peak of the 1970 season. This increase may be due to a general increase in numbers as a result of hunting being curbed, or it may be that turtles are attracted to Aldabra, it being one of the few islands where they are protected from poachers. Either way it is a good indication that devastated populations can be rehabilitated, but, ironically, the increase in nesting activity may in fact retard an increase in population size. A beach can become overpopulated with nesting turtles which as a result themselves destroy a high proportion of nests. So far Aldabra's main western beach, which represents nearly half the total nesting habitat, is little used, and it is essential to make this a suitable nesting area.

On Aldabra, as on other islands in the group and the Seychelles in general, there is considerable beach erosion. In some places it is seasonal, sometimes leading to large-scale nest destruction; in others it seems to be continual, leaving degraded beaches that are useless to turtles.

The finest turtle beach in all Seychelles is on Assumption, and large turtle populations nested here early this century - up to 400 females could strand in a single night. But in May 1973 the entire island had only 220 nest pits, 73 of them well over a year old, and another 60 certainly without eggs. I estimated the total at not more than 300 to 400 nests a year - the contribution of just 100 females! At the same time I found remains of 67 green turtles, mainly females, that had been poached.

In November/December that year there were 126 new nest pits but only 41 seemed to have eggs (i.e. the contribution of about a dozen females). Yet there were remains of 29 new females that had been poached since my last visit. My estimate again was 100 females nesting annually, and the same number being poached annually; that is, no female that nests on Assumption lives through the season.

THE POACHER'S WORK - even the meat is wasted, except by the hermit crabs.

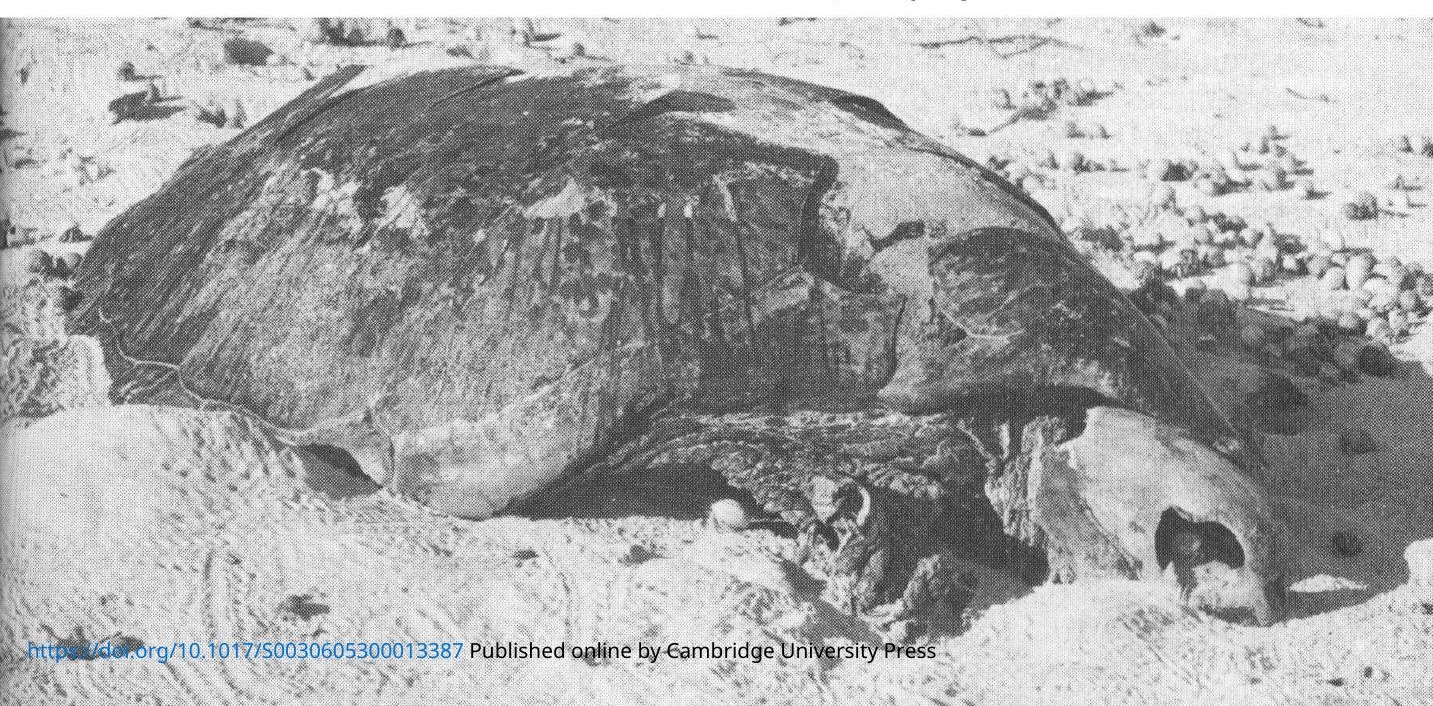


It is highly likely that the green turtle population could be rehabilitated at Assumption and once again be an important resource, but not while poaching continues.

A complete but brief reconnaissance of Astove atoll in June 1969 revealed the second largest nesting population in the Seychelles: 607 nest pits, of which 203 were on the large western beach. The nesting population was clearly several hundred in number, although far below 1000. But in 1972 the western beach had only 42 nest pits, of which 15 seemed to contain eggs. This dramatic decrease strongly suggests that the turtles are being disturbed and that the population has diminished since 1969. There must be well under 500 turtles nesting there now. Astove's eastern beaches suffer from extensive coastal erosion, so the nesting habitat is degrading also.

Of the eight major islands in Cosmoledo atoll I was able to see only four but these have the best nesting habitats: Wizard and Menai in 1968, and Menai, West North and East North in 1973. I found a total of 232 nest pits on the four, and it is very unlikely that more than a few hundred turtles are nesting. Cosmoledo has a number of small, but potentially good turtle beaches, and the reefs are rich and have large areas of marine pasture.

Hawksbills are said to be common on these raised reef islands of the Aldabra group, especially in the Cosmoledo lagoon. But the number breeding is insignificant. Neither on Astove nor Assumption was there any trace of hawksbills nesting. I have seen a few nests on Aldabra, and I suspect they nest on Cosmoledo although I have seen none. Two dozen females nesting a year is the maximum estimate for all four atolls together.

\section{Other Outer Islands}

I have not been able to visit this mixed group of islands, some of them raised reefs and others sand cays. Bird, Denis, Coetivy, Platte, Providence, Cerf, and Farquhar all have nesting turtles, but probably fewer than a dozen on each. I doubt if more than 100 green turtles breed here each year.

Hawksbills are said to be abundant on Coetivy, but rare on the other islands. I doubt if more than 100 nest annually.

\section{Poaching}

In Seychelles and BIOT the green turtle has been totally protected since 1968 . A ban of this nature is a complete "about face" from the previous overexploitation overtly practised, and its purpose is obviously to enable the populations to build up to a point where sustained-yield exploitation can be practised. Inevitably this law has provoked widespread opposition, and, as highlighted on Assumption, poaching continues unchecked. I have seen evidence of it on six islands and have reliable reports from another seven. The frequent claims made by Seychellois that Mauritian and "Japanese" fishermen are devastating the green turtles are emotional arguments and attempts to transfer the blame for what they are doing themselves.

Hawksbills are "protected" only when less than 24 inches long, and even this is not commonly enforced. This law is unfortunate, for it is the immatures (i.e. small animals) that are expendable, and the breeding adults, the large animals, that are vital to maintain the population which should be protected.

The importance of breeding reserves for both species cannot be overstressed. 
GLORIOSA ISLAND

Geologically Ile Glorieuse is related to the Aldabra group, having areas of raised reef limestone; politically it is one of four remote tropical islands administered by La Réunion, which is a French Department. It is run as a meteorological station, generally with a staff of four Réunionois. Early this century it was planted with coconuts. Little has been written about Gloriosa, but Seychellois speak of large numbers of green turtles captured there years ago. During the month I spent on the island, January/February 1972, 21 green turtle nests were made, representing at most 15 females. The total number of nest pits was 413 , and I estimated the maximum number of breeding turtles at 250 a year. Unfortunately, I could not return to the island to check for seasonal changes in nesting activity. Probably nesting activity increases in June and July, the peak nesting time on nearby Aldabra.

Despite a 6-km. stretch of ideal undisturbed beach, Gloriosa has very low nesting activity, especially compared with the nearby Aldabra islands. The most ready explanation for this anomaly is the large population of ghost crabs Ocypode spp. on the beaches. These burrow into nests and eat hatchlings, often destroying an entire nest. They also patrol beaches, taking emerging hatchlings. Groups of turtles were common offshore and it is possible that Gloriosa is a transit stop in migrations to and from feeding and breeding areas.

I found three hawksbill nests during the month I was on Gloriosa, and 23 hawksbill nest pits. The annual nesting total is unlikely to exceed 50. This, too, is puzzling, for in addition to the large beach, Gloriosa has a vast reef area which must provide a large amount of hawksbill food.

Gloriosa is a nature reserve and may soon become a national park, along with Europa Island at the other end of the Mozambique Channel, a farsighted move on the part of the Réunion Government, which I hope will also enforce the protective legislation.

\section{COMORO ARCHIPELAGO}

The Comores, a French Territoire d'Outre Mer, declared unilateral independence on June 6, 1975. The four major islands vary considerably in age, altitude, vegetation, inshore waters, and importance to breeding and feeding turtles. All are volcanic and geologically young. I visited them in 1972, with another short visit in 1973.

\section{Grande Comore (Ngazydia)}

The largest and geologically youngest of the Comores, with an active volcano, Kartala, of $2363 \mathrm{~m}$, this island rises steeply from the ocean floor and so has little shallow water. Fringing coral reefs are small and marine pastures insignificant. The coast is mainly rough lava, and usable beaches for turtles are few, and much disturbed by the large human population. I was told of individual records of nesting at Chindini (in the south) and Mitsamuli (in the north), but personally saw no evidence of nesting at all, although I did not see some of the eastern beaches.

Hawksbill and green turtles are commonly caught in fishing nets set in the Mitsamuli area. Of seven hawksbills measured, six were under $60 \mathrm{~cm}$ long (curved length of carapace), and only one was more $(67 \mathrm{~cm}$ ) and hence likely to have been adult. The green turtles measured 50 to $60 \mathrm{cms}$ and were 
certainly immatures. Whether or not Grande Comore is an important area for immatures is a mystery; it is clearly not important for nesting.

\section{Moheli}

Moheli is the most important island for turtles, with more green turtles breeding than at any other island in the area. It is the smallest and least densely populated of the Comores. Virtually encircled by fringing coral reefs and expanses of marine pastures, Moheli has some ninety beaches, of which thirty had signs of turtle-nesting, and six were intensively used. In 1972 I estimated the nesting females to number between 150 and 200 a year at each of five beaches, and 600 at the sixth. My total estimate for all beaches together was 1900 .

In June 1973, on the five important beaches I was able to visit, nesting activity was similar to 1972: the first (often visited by turtle hunters) showed a decrease, the second was virtually the same, the third showed a possible small decrease, the fourth had a small but encouraging increase, and the fifth was not comparable.

On two of these beaches, in 1972, villagers commonly killed turtles for the meat, but fewer had apparently been killed in 1973. On the most important beach, cropping was low enough in 1972 to be tolerable. But feral dogs pose a considerable problem, digging up large numbers of eggs and hatchlings (and also ravaging the goat herds) - there seems good reason to control them.

Hawksbills were commonly seen on the rich coral reefs in the south, but I found only 17 nests distributed over 11 beaches, which suggests that Moheli is not important for hawksbill nesting, although it may be for feeding.

\section{Anjouan}

Densely populated, with heavy pressure on food and other resources, Anjouan seems of little importance to turtles for either feeding or nesting. The beaches I saw were not good for turtles, and the fringing reef is not rich, although heavily exploited for food and coral. I was told of turtles nesting but doubt if the number is significant.

\section{Mayotte}

With one of the finest reef systems in the western Indian Ocean, Mayotte is the most ancient of the Comores. Between the barrier reef and the coastal fringing reefs, which are rich with corals, fish and other marine life providing excellent feeding for hawksbills, is a vast lagoon, dotted with islands. Marine pastures cover extensive areas in the quiet lagoon waters, and must provide excellent feeding for green turtles.

Altogether Mayotte and its satellite islands have over 140 beaches, but three-quarters of them have villages, boats, or some other form of human disturbance. Only on seventeen was there evidence of nesting, and only four had more than an estimated dozen females nesting per year. Three of these beaches were on Pamanzi Island. In a two-week period eleven nests were made and eight females killed on these three beaches. My final estimate was 300 females on Pamanzi and 500 on the whole of Mayotte.

As usual, there was scant evidence of hawksbills laying. I suspect they nest occasionally on Pamanzi, but probably not more than a few dozen a year.

In 1973 the situation on Pamanzi appeared unchanged. The rate of exploita- 
tion is excessive. The chances a female will live after stranding on a beach are 50:50. Considering that not all strandings end in eggs being laid and that one female lays several times in a season the chances are 100-to-one against a female living through a season.

There is no effort and no legislation in Comores to conserve and manage the turtle resources. A close look at Mayotte suggests that nesting activity is below what it ought to be; a number of good beaches are not used at all or only very occasionally. The turtles are being heavily over-exploited, and this could easily be the cause of a large scale decrease in numbers and resultant abandoning of breeding beaches.

A conservation awareness, and education in these problems is badly needed.

MADAGASCAR

This immense island, or sub-continent, the Malagasy Republic, has been independent of French colonial rule since 1960. The coast shows great variation, from mountainous and humid in the north to low and arid in the south. I investigated the offshore islands in the north-west, which are difficult to get to, so information on them is scanty; but by the same token they should be the least disturbed and hence a good index of what the nesting populations are at their best.

\section{Mitsio Islands}

Nossi Mitsio is the largest of a group of small islands north of Nossi Be, many of volcanic origin. Eleven beaches totalling over twelve kilometres produced three nests, although there was good nesting habitat. The east coast, which I did not visit, has considerable human disturbance and is not likely to change the overall picture.

Nossi Ankarea, west of Nossi Mitsio, had a good beach but no turtles. There was no certain nesting on Tsara Bajina's six small beaches, but their nesting potential was not outstanding. The nesting total for the islands seems to be under a dozen.

\section{Nossi Be}

A quick look at Nossi Be, Nossi Komba, Tani Keli, and other islands in this region showed no sign of nesting turtles, but a great amount of human activity.

\section{Nossi Iranja}

The main island had little sign of nesting, but on the offshore sand cay, on a beach only a few hundred metres long, I saw more nests than anywhere else in Madagascar: thirty-one nest pits, many recent, and about two-thirds with eggs. However, probably well under 100 females breed annually.

\section{Isles Radama}

I only visited Nossi Kalankarjoro in this group, and only one of its three beaches. This was over $200 \mathrm{~m}$ long with good nesting potential, and evidence of hawksbill nesting, but probably not more than a dozen.

Although I saw a very small proportion of the Madagascar beaches, the very low level of nesting on remote islands with small human populations is 
significant - and depressing. Early accounts of Madagascar indicated a richness of turtles, but my findings, and the findings of Dr George Hughes, who made a more complete survey of the mainland, strongly suggest that the turtle populations are now at a very low breeding level. George Hughes found predation to be very intense.

In theory green turtles are protected, but the legislation is not enforced.

\section{Summary and Conclusions}

My total estimate was fewer than 5500 green turtles nesting annually in an area of ocean and islands covering over a million square miles. And it must be emphasised that all my estimates are maximal; using the data more strictly would undoubtedly yield significantly smaller estimates. Table 1 shows that the significant contributions to green turtle populations come from the Aldabra group and Moheli in the Comores. But eighty years ago 12,000 turtles were captured in one year at Aldabra alone; even 60 years ago 9000 were taken there, and on Assumption up to 400 females were stranding on the main beach in one night. Even if my estimates are badly in error, it is unlikely that the general picture of a catastrophic decline in the green turtle populations will be disproved.

The hawksbill picture is not nearly so dramatic, but it is almost certainly following the same downward trend.

The two important reasons for the green turtle catastrophe are overexploitation and destruction of habitat (by man). As the exploitation is exceptionally heavy on nesting females, the end result is a severe fall in reproduction and recruitment; at the same time man's use of the beaches makes them unusable or unsuitable for nesting turtles. Regardless of how many turtles there are, they soon have nowhere to nest. It is this second point - the destruction of habitat - that is so poorly understood, but soon turtles in the Indian Ocean will have nowhere to nest outside reserves such as Cousin Island. Complete protection and efficient law enforcement will never be achieved in this vast area, for as long as there are people there will be poachers. The problem is to concentrate on and protect the most important breeding areas. Only international co-operation will achieve this.

\section{Acknowledgments}

To list all the people who helped with the project is impossible; of some I do not even know the names. However, much of the work was made possible by generous support from the Fauna Preservation Society; work on Aldabra was supported by the Natural Environment Research Council (NERC) and the Royal Society; work in the Seychelles area was done while I was employed by the Seychelles Government, and as a member of the Seychelles Coral Reef Conservation Expedition; work on Gloriosa and the Comores was greatly aided by the Meteorological Departments of Réunion and Comores. Numerous friends and colleagues also helped in many ways: expedition members, staffs of the Seychelles Department of Agriculture and of the Meteorological Departments, and island owners and managers; also Halidi Mohammed Abdullah and family, Professeur F. Bourlière, Jean Claud Boyer, Harry Charles, Marimba, Nigel and Gwen Cornfield, Charles Deltour, Dr Tony Diamond, Professor J. Dorst, Capt. Garzensky, Dr Roland von Hentig, Dominique and Theo Laurette and family, René Legrand and family, Armand Lienard, David Lloyd, Inspector Loisance, Drs F. and A. Malandain, Marcel Malick, Abdullah Moindraze, Jean Nicolla, John Procter and family, Philippe Richeux and family, Capt. G. Savy, and Capt. T. M. Williams. 
Annual Nesting Estimates

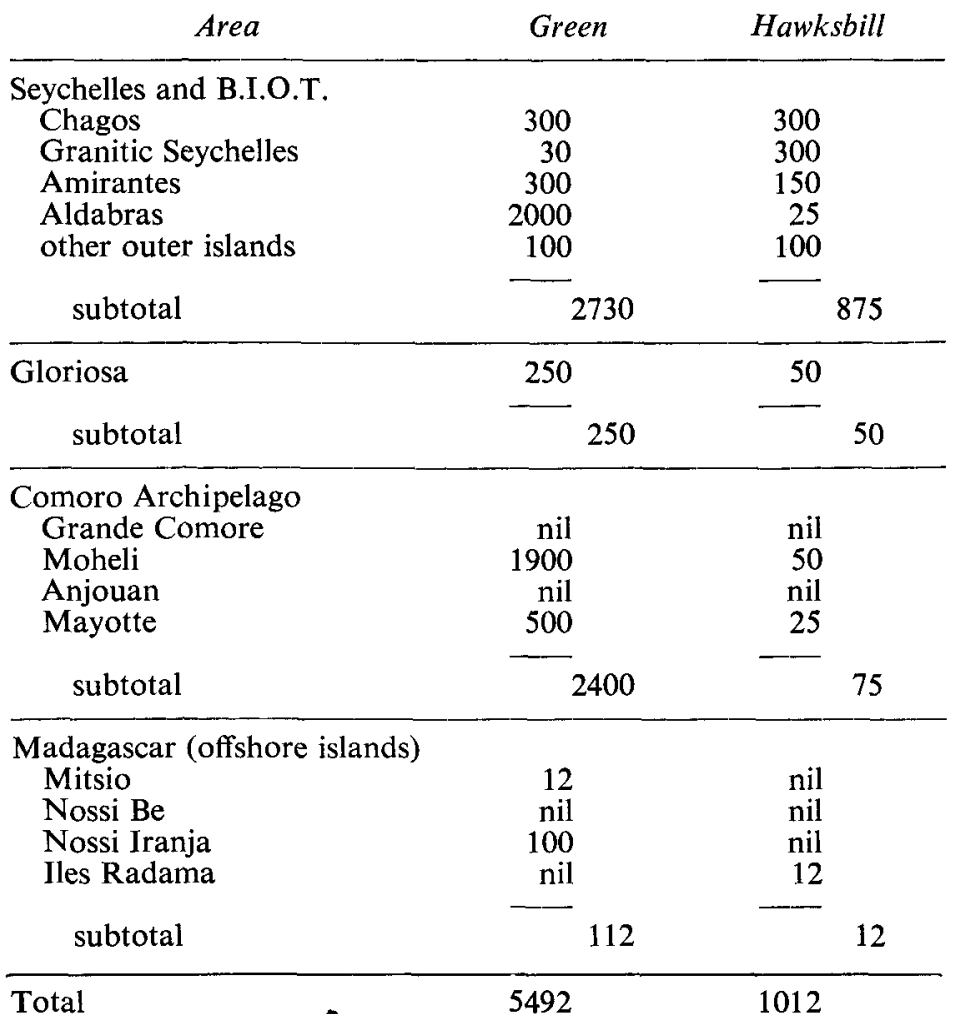

\section{Bibliography}

F.A.O. 1967. Report to the Governments of the People's Republic of Southern Yemen, and the Seychelles Islands on the green turtle resource of South Arabia, and the status of the green turtle in the Seychelles Islands. Based on the work of Dr H. Hirth. Rep. FAO/UNDP(TA), (2467): 59pp.

FRAZIER, J. 1970. Report on Sea Turtles in the Seychelles Area. Mimeographed, 96pp.

FRAZIER, J. 1972. Marine Turtles in the Archipel des Comores. Typescript, 29pp.

FRAZIER, J. 1972. Preliminary report on studies on Gloriosa Island. Longhand, 28pp.

FRAZIER, J. 1973. Terminal report (to the Conservation Adviser, Seychelles Government). Mimeographed, 25pp.

FRAZIER, J. 1974. Biological Conservation, 6(1): 71-73.

HUGHES, G. R. 1971. Preliminary report to the Southern Africa Wildlife Foundation (World Wildlife Fund) on the status of sea-turtles in south-east Africa. Section 2: Madagascar and the Mascarenes. Oceanographic Research Inst. Int. Rep., Mimeographed, 47pp.

HUGHES, G. R. 1972. Biological Conservation, 4 (2): 128-134.

HUGHES, G. R. 1973. Biological Conservation, 5 (2): 114-118.

PARSONS, J. 1962. The green turtle and man. Gainesville: Univ. of Florida Press. $126 \mathrm{pp}$.

All photographs in this article are by the author. 